\title{
Nieuwe thema's in het psychologisch onderzoek naar arbeid en organisatie
}

In augustus 2005 werd in Okayama, Japan, de tweede $\mathrm{ICOH}$-conferentie over Psychosociale factoren in het werk gehouden. ICOH is de afkorting van de International Commission on Occupational Health. Aan de driejaarlijkse wereldcongressen van ICOH doen zo'n 3000 onderzoekers mee. ICOH heeft 35 wetenschappelijk comités, waaronder het Work Organisation \& Psychosocial Factors (ICOH-WOPS)-comité dat deze Japanse conferentie organiseerde.

In dit veslag beschrijven we de in onze ogen opvallende 'emerging issues' in het psychologisch onderzoek rond werk en werkomstandigheden. Uiteraard kan enige subjectiviteit daarbij niet vermeden worden.

Eerst enige 'facts \& figures'. In drie dagen werden er 160 mondelinge presentaties gegeven en waren er ruim 300 posters. Zoals gebruikelijk op dit terrein waren onderzoekers uit Zweden, Denemarken, Nederland, Engeland, de VS en Canada het best vertegenwoordigd. Gezien de plaats van de conferentie waren er ook relatief veel onderzoekers uit Japan, China en Korea.

De meeste presentaties waren uiteraard gewijd aan onderwerpen als stress en burnout, ziekteverzuim, 'terugkeer naar werk' ('return to work'), veiligheid en ongevalsrisico, werktijden en overwerk, de 'work-life balance', het inmiddels wel erg uitgebeende Job Demands-Job Control model en interventiestudies. Maar in feite zijn dit geen echt nieuwe thema's. Ook het hameren op de wenselijkheid van longitudinaal onderzoek is al jaren aan de gang, en dus niet nieuw. Een van de keynote speakers (Wilmar Schaufeli ${ }^{1}$ ) vond gelukkig dat 'de ban op cross-sectioneel onderzoek' overdreven werd en veel te ver ging.

Ons inziens waren de vier echt opkomende en min of meer nieuwe thema's:
1. De 'positieve psychologie' als tegenkracht tegen de psychologie die zich bezighoudt met 'negatieve' meningen en gedrag van werkenden.

2. Trends in werk en werkomstandigheden.

3. 'Presenteeism' als tegenhanger van 'absenteeism'.

4. 'Emotional labor' als aanvulling op werkdruk en fysiek zwaar werk.

Aan de hand van de conferentiebijdragen en eerder gepubliceerde artikelen zullen we deze vier thema's nu achtereenvolgens de revue laten passeren.

De Amerikaanse psychologen Martin Seligman en Mihaly Csikszentmihalyi worden gezien als de activatoren van de positieve psychologie. ${ }^{2}$ Zij bepleitten in het jaar 2000 een psychologie die het als haar primaire taak zou zien om te begrijpen waarom het leven waard is om geleefd te worden. Waarom zijn werknemers gelukkig en tevreden? Wie zijn het? Hoe komt dat? Voorts was hun boodschap: Gelukkig zijn en optimistisch in het leven staan kun je leren. In 2001 schreven de Utrechtse A\&O-psychologen Wilmar Schaufeli en Arnold Bakker een pleidooi voor een positieve benadering in de arbeid- en organi-satiepsychologie. ${ }^{3} \mathrm{Zij}$ concludeerden dat de A\&O-psychologie vooral gericht is op de oorzaken van ongezondheid, onwelbevinden, burn-out, stress en verzuim, en dat het tijd werd meer aandacht te besteden aan de oorzaken van plezier in het werk, tevredenheid met het werk, vitaliteit/energie en identificatie met het werk of 'commitment'. We zijn vier jaar verder en hun oproep is gedeeltelijk geslaagd. Genoemde auteurs hebben de 'en-gagement'-vragenlijst ontwikkeld, die bevlogenheid in het werk meet. Deze is inmiddels uitgetest in Finland, Japan en Zuid-Afrika. Volgens een Japanse congresbijdragen bleek bevlogenheid gerelateerd te zijn aan een actieve wijze van omgaan met problemen in het werk ('problem solving coping'), maar ook aan arbeidstevredenheid en werkprestaties. Een Zuid- 
Afrikaanse studie toonde aan dat bevlogenheid deels verklaard wordt door persoonskenmerken als extraversie en emotionele stabiliteit. Nederlandse data van Schaufeli lieten zien dat bevlogenheid te maken heeft met het werk maar vooral met de persoonlijkheid. Tenslotte tonen resultaten van de TNO Arbeidssituatie Survey 2002 $(\mathrm{TAS})^{4}$ aan dat bevlogenheid in Nederland met name samenhangt met leeftijd (ouderen zijn bevlogener; mogelijk is hier sprake van een selectie-effect omdat de minder bevlogenen werkloos of arbeidsongeschikt zijn) en met werkkenmerken als autonomie en variatie in het werk en complex werk. De oorzaak-gevolgrelatie staat hier natuurlijk nog open. Het kan namelijk heel goed zijn dat zelfstandig en gevarieerd werk tot bevlogenheid leidt en onzelfstandig en saai werk tot afwezigheid van enige betrokkenheid bij het werk. Alles bij elkaar lijkt de positieve A\&O-psychologie een inspirerende leidraad te zijn. De invalshoek zou wellicht nog wat meer navolging verdienen.

'Trends in work' werden in het Japanse congres belicht met Deense en Nederlandse data, terwijl de discussie liet zien dat ook in de VS en Zweden ${ }^{5}$ ruime aandacht bestaat voor dreigende en opwekkende ontwikkelingen in werk en werkomstandigheden. Uit de data van het Deense Arbeidsomstandigheden Instituut (AMI) ${ }^{6}$ bleek dat in de periode 1990-2000 onder meer een toename te constateren was van computergebruik, lawaaiblootstelling en autonomie in het werk. De Nederlandse congresbijdrage $^{7}$ met data afkomstig van het CBS over de periode 1994-2003, liet zien dat er een afname te constateren was in de werkdruk (na een lange periode van toename van werkdruk in de jaren 80 en begin jaren 90) evenals een afname van loontevredenheid, wellicht samengaand met de economische neergang. De Deense data werden bevestigd wat betreft de stijging van de autonomie in het werk. Geen veranderingen waren er waar te nemen in de fysieke werkomstandigheden en arbeidstevredenheid. In het algemeen laten de Nederlandse data zien dat veranderingen langzamer gaan dan wel eens gedacht wordt. De trend dat werknemers meer zelfstandigheid of autonomie in het werk ervaren is opvallend en toont aan dat de recente aanklacht van een aantal filosofen in de $N R C$ en de Volkskrant tegen de managers in Nederland, die de werknemers machteloos zouden maken, ongegrond is.

Het derde 'emerging issue' in de conferentie was het accent op 'presenteeism' als tegenhanger van 'absenteeism' ofwel ziekteverzuim. Vijf jaar geleden was de Zweed Gunnar Aronsson van het National Institute of Working Life in Stockholm de eerste auteur die dit thema behandelde. ${ }^{8}$ Ongeveer $50 \%$ van de Zweedse werknemers was minimaal één keer in de 12 maanden naar het werk gegaan, terwijl hij dacht dat hij zich - gezien z'n gezondheidstoestand - eigenlijk ziek had moeten melden. In de gezondheidszorg- en onderwijssectoren bleken deze percentages het hoogst te liggen. Uit de congrespresentatie van de Deen Claus Hansen, ${ }^{9}$ bleek zelfs $72 \%$ van de werkenden in Denemarken ten minste één keer in 12 maanden ziek naar het werk gegaan te zijn. Resultaten van de TNO Arbeidssituatie Survey 2002 laten zien dat in Nederland de percentages tussen 60 en $65 \%$ liggen. ${ }^{10}$

Tijdens dit symposium liet Eva Demerouti van de Universiteit van Utrecht ${ }^{11}$ zien dat 'presenteeism' en 'uitputting' wederkerig met elkaar in verband staan. Dus uitputting leidt tot zieke aanwezigheid en zieke aanwezigheid leidt tot uitputting. Het is goed dat het begrip 'presenteeism' ontwikkeld en getest is. De cijfers geven namelijk wat tegenwicht tegen de veronderstelling dat er in Nederland zoveel zwart en grijs verzuim bestaat. De conclusie moet eerder zijn dat dat er zeker verzuimd wordt op wat zwakke gronden, maar ook dat er veel werknemers zijn met een groot plichtbesef die zelfs halfziek hun verplichtingen proberen na te komen.

Meer en meer worden onderzoekers, adviseurs en andere practici zich ervan bewust dat de eisen die het werk stelt aan werknemers niet alleen kwantitatief en cognitief maar eveneens emotioneel van aard zijn. 'Emotional labor' als aanvulling op fysiek zwaar werk lijkt een opkomend thema. Dit heeft onder meer te maken met het inkrimpen van fysiek zware bedrijfstakken als de landbouw en de industrie, en de continue groei van de dienstensector met alle emotioneel belastende klantcontacten van dien. Men kan hierbij denken aan het beroep van docent, verpleegkundige, baliemedewerker, bus- en trambestuurder, receptionist, etc. In al deze beroepen is klantvriendelijkheid en service geboden. In een van de congresbijdragen was zelfs sprake van 'frontline hotel employees in India'. Emotionele taakeisen worden onder meer gemeten met de Copenhagen Psychosocial Questionnaire ontwikkeld door Tage Kristensen van het Deense Arbeidsmillieu Instituut ${ }^{12}$ en met de TNO Arbeidssituatie Survey ${ }^{13}$ in Nederland. In een Japanse bijdrage werd aangetoond dat emotionele taakeisen depressiegevoelens tot gevolg hebben.

Alles bij elkaar leverde dit tweede ICOH congres over psychosociale factoren in het werk in een drietal dagen impulsen op voor nieuwe onderzoeksprojecten en inspiratie voor secundaire analyses op beschikbare databestanden. En ook hernieuwd enthousiasme voor internationale samenwerkingsverbanden, want wat zo'n congres aantoont, is dat de Europese gemeenschap alsook het internet - gezien het ruime aantal cross-culturele of cross-nationale studies - de internationale samenwerking steeds verder versterkt. En dat komt de kwaliteit van het onderzoek ten goede.

Peter Smulders \& Irene Houtman TNO Arbeid, Hoofddorp 


\section{Literatuur}

Schaufeli WB. New organizational practices and worker health: current understanding and research challenges. Second $\mathrm{ICOH}$ International Conference on Psychosocial Factors at Work, 23-26 August 2005, Okayama, Japan.

Seligman AEP, Csikszentmihalyi M. Positive psychology: an introduction. Am Psychol 2000; 55: 5-14.

Schaufeli W, Bakker A. Werk en welbevinden: naar een positieve benadering in de arbeid- en gezondheidspsychologie. Gedrag Organisatie 2001; 229-253.

Smulders PGW. Netherlands: older workers more motivated in their work European Foundation for the improvement of Living and Working Conditions, Dublin, News Update, 14 May 2004, http://www.eurofound.eu.int/ewco/2004/05/ NL0405NU04.htm.

Gustafsson RA, Lundberg I. Worklife and health in Sweden 2004. Stockholm: National Institute for Working Life, 2005.

Zie ook: Burr H, et al. Trends in the Danish work environment in 1990-2000 and their associations with labor-force changes. Scand J Work Environ Health 2003; 270-279.

Zie ook: Houtman ILD, Smulders PGW, Klein Hesselink DJ. Trends in arbeid 2004. Hoofddorp: TNO Arbeid, 2004.
Aronsson G, Gustafsson K, Dallner M. Sick but yet at work: an empirical study of sickness presenteeism. J Epidemiol Commun Health 2000; 54: 502-509.

Hansen CD, Andersen JH. Predictors of sickness presence: who works when ill, how often and for what reasons? Results from a Danish population based study. Second ICOH International Conference on Psychosocial Factors at Work, 23-26 August 2005, Okayama, Japan.

Smulders PGW.Netherlands: presenteeism among sick workers. European Foundation for the Improvement of Living and Working Conditions, Dublin, News Update, 11 December 2003, http://www.eurofound.eu.int/ewco/newsupdates_2003. htm.

Demerouti E, Bakker A, Blanc P Le, Schaufeli W. Job demands, burnout and presenteeism: a three-wave study. Second ICOH International Conference on Psychosocial Factors at Work, 23-26 August 2005, Okayama, Japan.

Kristensen TS. A new tool for assessing psychosocial factors at work: The Copenhagen Psychosocial Questionnaire (COPSOQ). Copenhagen, National Institute of Occupational Health, 2002.

Ybema JF, Smulders P. Emotionele belasting en de noodzaak tot het verbergen van emoties op het werk. Gedrag Organisatie 2002; 15: 129-146. 